\title{
Papers
}

\section{Promotion to hospital consultant: regression analysis using NHS administrative data}

Kostas Mavromaras, Anthony Scott

\begin{abstract}
Objectives To examine factors influencing promotion to hospital consultant.

Design Multivariate logistic regression analysis of NHS administrative data between 1991 and 2000.

Setting Hospitals in NHS Scotland.

Population All registrars, senior registrars, and specialist registrars in Scotland.
\end{abstract}

Main outcome measure The proportion of doctors promoted to NHS consultant.

Results Compared with doctors who graduated in Scotland, graduates from the rest of the United Kingdom and from overseas were less likely to be promoted to consultant (odds ratio $0.65,95 \%$ confidence interval 0.52 to 0.82 ; and $0.37,0.28$ to 0.50 , respectively). Promotion and holding an honorary contract before promotion were positively associated $(1.37,1.03$ to 1.83 ); and the number of years since graduation (5.98 per year, 4.94 to 7.23$)$. Women were less likely to be promoted $(0.73,0.60$ to 0.90$)$, as were doctors who worked part time $(0.27$, 0.17 to 0.42 ). Probabilities of promotion did not have a clear time trend between 1993 and 2000, and NHS boards in non-metropolitan areas of Scotland were more likely to offer promotions than NHS boards in metropolitan areas, presumably reflecting a higher gap between demand and supply in these boards.

Conclusion As the proportion of women in hospital medicine increases, government targets for the recruitment of consultants are unlikely to be met unless the promotion process is examined. It is unclear whether more recent reforms of the medical career structure will deal with these issues.

\section{Introduction}

The NHS Plan, and its equivalent in Scotland, set ambitious targets for the recruitment of more consultants. ${ }^{12}$ With a time lag between being trained and being a fully qualified specialist of at least 10 years, policies such as the increase in the number of places at medical schools will not influence the number of consultants in the short term. By contrast, reducing the threshold for promotion to consultant could achieve short term recruitment targets. The latest policy discussed is reducing the length and nature of specialist training. ${ }^{3}$ With a fixed number of hospital doctors, a lowering of the threshold of promotion will produce more consultants but will also increase costs without necessarily increasing quality of care.

One issue that is not well understood is the process of promotion to hospital consultant. The career track to becoming a consultant is competitive, and little empirical evidence exists about which doctors are promoted. Simple comparisons of consultants with other trained doctors (general practitioners, staff grade doctors, and associate specialists) show that consultants are more likely to be male, from a white ethnic background, and in full time positions. ${ }^{4}$ This may reflect several factors including promotion criteria, the distribution of new consultant posts and vacancies across specialties and geographical areas, the preferences of interview panels, and the experience and abilities of doctors applying for promotion. Increasingly, becoming a general practitioner, staff grade doctor, or associate specialist are attractive options for male as well as female doctors with strong preferences for working less than full time. Rigid training requirements may also mean that doctors who trained overseas cannot easily become consultants in the United Kingdom.

We examine the role of several factors associated with promotion to NHS consultant in Scotland. We focus on the role of sex, country of qualification, hours of work, and the nature of training. We used a multivariate framework that controls for years of experience and other factors that are likely to be correlated with these variables and with promotion, such as specialty.

\section{Method}

\section{Data}

We obtained data from the medical and dental census from 1991 to 2000 from the information services division of NHS Scotland. These data include all doctors and dentists working in hospital and community health services. The data are used to produce official NHS workforce statistics and are collected by hospitals that send a return to the information services division each time a doctor or dentist has joined or left. The data represent the total population of doctors and dentists working in Scotland at 30 September each year. We used a unique identifier for doctors to link each census for each year. The data contain information, at an individual level, on age, sex, ethnicity, country of qualification, years since graduation, full time or part time contract, honorary contract, whole time equivalents, specialty, grade, hospital, and NHS board.

To analyse promotion, we excluded all consultants at the start of the observation period from the sample as they had already been promoted. We also excluded individuals observed for only one year, as we did not follow their promotion. Promotions to consultant could not be observed where the job in the year before promotion was outside Scotland: only promotions from within NHS Scotland can be considered. The sample was restricted to doctors who were in the following grades in any given year over the period: registrar, senior registrar, and specialist registrar. This represents the pool of those doctors who could have potentially been promoted to consultant between 1991 and 
Table 1 Doctors promoted to consultant in Scotland, by year and sex

\begin{tabular}{|c|c|c|c|c|c|c|c|c|c|}
\hline No of doctors in each year & 1993 & 1994 & 1995 & 1996 & 1997 & 1998 & 1999 & 2000 & $\begin{array}{l}\text { Total person years and average } \\
\text { annual incidence of promotion }\end{array}$ \\
\hline \multicolumn{10}{|l|}{ Women } \\
\hline Not promoted & 184 & 212 & 248 & 321 & 375 & 389 & 390 & 407 & 2526 \\
\hline Promoted & 22 & 20 & 35 & 26 & 41 & 35 & 47 & 39 & 265 \\
\hline$\%$ promoted & 10.7 & 8.6 & 12.4 & 7.5 & 9.9 & 8.3 & 10.8 & 8.7 & 9.5 \\
\hline Total & 206 & 232 & 283 & 347 & 416 & 424 & 437 & 446 & 2791 \\
\hline \multicolumn{10}{|l|}{ Men } \\
\hline Not promoted & 360 & 368 & 421 & 469 & 509 & 540 & 499 & 481 & 3647 \\
\hline Promoted & 38 & 48 & 88 & 91 & 94 & 70 & 100 & 76 & 605 \\
\hline$\%$ promoted & 9.5 & 11.5 & 17.3 & 16.3 & 15.6 & 11.5 & 16.7 & 13.6 & 14.2 \\
\hline Total & 398 & 416 & 509 & 560 & 603 & 610 & 599 & 557 & 4252 \\
\hline \multicolumn{10}{|l|}{ All doctors } \\
\hline Not promoted & 544 & 580 & 669 & 790 & 884 & 929 & 889 & 888 & 6173 \\
\hline Promoted & 60 & 68 & 123 & 117 & 135 & 105 & 147 & 115 & 870 \\
\hline$\%$ promoted & 9.9 & 10.5 & 15.5 & 12.9 & 13.2 & 10.2 & 14.2 & 11.5 & 12.4 \\
\hline Total & 604 & 648 & 792 & 907 & 1019 & 1034 & 1036 & 1003 & 7043 \\
\hline
\end{tabular}

The sample includes all doctors in NHS Scotland on September 30 each year between 1993 and 2000 in the grade of registrar, senior registrar, and specialist registrar.

Observations from 1991 and 1992 were not included in the model because two of the independent variables were lagged by two years.

2000. Doctors who were not promoted in a particular year remained in the pool in the following year. After doctors became consultants they were not included in the following years' data.

\section{Statistical methods}

We used conditional fixed effects logistic regression. ${ }^{56}$ The dependent variable took the value one for doctors who were consultants in the current year and not consultants in the previous year (promotion), and zero for others (no promotion). This estimation method controls for unobserved differences in promotion probabilities attributable to specialties, such as differences in demand and training for consultants across specialties alongside other unobserved factors leading to a different likelihood of promotion across specialties (unobserved heterogeneity). The general form of the model estimated here is similar in structure to a linear error components model or a multilevel model:

$y_{i j}=X_{i j} \beta+v_{i j}$

where the error term consists of two components,. The data contains $j$ individuals (the doctors), each of whom belong to one of the $i$ categories (the hospital specialties). $X_{i j}$ and $y_{i j}$ are the observed data, and $\beta$ are parameters to be estimated. The specialty specific component of the error term $s_{i}$ is assumed to be a fixed parameter to be estimated, and $u_{i j}$ is assumed to be the customary independent and identically distributed error term. The fixed effects modelling framework is appropriate here as we focus on a specific set of $i$ groups, the hospital specialties, and inference is conditional on these groups. A further advantage of this model is that it allows for consistent estimation when the specialty-specific effects $s_{i}$ are arbitrarily correlated with the observed $X_{i j}$ (as one would expect here, individual doctors' characteristics will be correlated with specialties). The above equation is, for ease of exposition, a linear version of the fixed effects model. The model estimated is a non-linear logistic fixed effects regression. We report odds ratios and $95 \%$ confidence intervals. We used Stata 8/SE for estimations. ${ }^{7}$

Independent variables included sex and country of qualification. We also included whether an honorary contract was held in either of the two years before promotion. This reflects the importance of research experience in the promotion process. We used two year lags to acknowledge the possibility that the promotion value of such contracts may take more than one year to be realised. We used years after graduation and their square to approximate years of professional experience. This may be a biased estimate of experience as the net time spent working as a doctor will be lower among those who have worked part time at some point in their career. We therefore weighted this variable by the mean whole time equivalents observed for each individual. As weighted and unweighted variables produced similar results, only unweighted results are presented.

A variable indicating whether a doctor held a part time contract in either of the two years before promotion was included. The change from part time to full time between the two years before promotion was included as a variable to reflect possible higher promotion chances. The use of two year old information for this and for the honorary contract variable restricted the estimation sample to the years of 1993-2000. The model also included a set of year dummy variables to capture any trends in promotion rates over the time frame of the data. A set of NHS health board dummy variables were also included to account for differences in demand at NHS health board level and supply of consultants and factors such as teaching status.

\section{Results}

Tables 1 and 2 show the characteristics of the sample, which included 2716 individual doctors, comprising a total of 7043 person year observations, in the promotion pool between 1993 and 2000. Over the 1993-2000 period, 870 (32\% of 2716 individuals) doctors were promoted to consultant from within NHS Scotland. The average yearly incidence of promotion to consultant during the 1990 s was $12.4 \%$ (9.5\% for women and $14.2 \%$ for men). Apart from 1993, men were more likely to be promoted than women in each year, although no clear trends over time emerged (table 1). Altogether $37.9 \%$ of doctors in the sample were female, $66.9 \%$ had qualified in Scotland, $20.5 \%$ in the rest of the UK, and $12.6 \%$ in other countries. The average experience since graduation was 9.4 years. An honorary contract was held by $8.2 \%$ of doctors, and $5.5 \%$ of the sample held a part time contract. A higher proportion of women than men had qualified in Scotland. Women were less likely to have held an honorary contract and more likely to have worked part time and to have changed from working part time to full time.

Table 3 shows the regression results for the full sample and separately for women and men. The results are robust to different specifications of the model. The odds ratios are adjusted for the other covariates in the model and for the additive linear 
Table 2 Characteristics of hospital doctors in promotion pool (between 1993 and 2000). Values are numbers (percentages) of doctors unless otherwise indicated

\begin{tabular}{lcccc} 
& $\begin{array}{c}\text { Full sample } \\
(\mathbf{n}=\mathbf{2 7 1 6})\end{array}$ & $\begin{array}{c}\text { Women } \\
(\mathbf{n}=\mathbf{1 0 2 9})\end{array}$ & $\begin{array}{c}\text { Men } \\
(\mathbf{n}=\mathbf{1 6 8 7})\end{array}$ \\
\hline Qualified in Scotland & $1892(66.9)$ & $764(74.2)$ & $\begin{array}{c}1053 \\
(62.4)\end{array}$ \\
\hline Qualified England, Wales, or Northern Ireland & $558(20.5)$ & $181(17.6)$ & $377(22.3)$ \\
\hline Qualified outside the UK & $341(12.6)$ & $84(8.2)$ & $257(15.2)$ \\
\hline Honorary contract (yes=1) ${ }^{\star}$ & $223(8.2)$ & $61(5.9)$ & $162(9.6)$ \\
\hline Female (yes=1) & $1029(37.9)$ & & - \\
\hline Mean No of years since graduation (SD) & $9.36(3.93)$ & $8.82(4.03)$ & $9.69(3.83)$ \\
\hline Mean No of years since graduation squared/100 (SD) $\dagger$ & $1.04(0.99)$ & $0.95(0.97)$ & $1.10(0.99)$ \\
\hline Part time contract (yes=1) & $149(5.5)$ & $136(13.2)$ & $12(0.7)$ \\
\hline Change from working part time to full time (yes=1) & $45(1.7)$ & $41(4.0)$ & $4(0.2)$ \\
\hline
\end{tabular}

*In the two years preceding promotion.

†Age squared is used as an explanatory variable along with age in order to explore the nature of the relationship between promotion and age (linear if age squared shows no statistical

significance, or quadratic if it does).

effect of unobserved differences in promotion incidence across specialties.

In the full sample, Scottish medical graduates (the reference category) had the highest chance of getting promoted, followed by graduates from the rest of the UK. Doctors who had qualified outside the UK were least likely to get promoted. Doctors who had held an honorary contract during at least one of the two years before promotion were more likely to get promoted than those who had not. Promotion chances have a quadratic relation with the number of years since graduation; they rise at first and then fall, after a peak at 16 years after graduation. Doctors on a part time contract in at least one of the two years before promotion have lower promotion probabilities than doctors working full time. Doctors who increased their hours by changing from part time status to full time status in the years before promotion had a higher chance of getting promoted, but this association did not reach significance. These results have controlled for year, NHS board, and specialty effects. The year dummy variables (not shown) showed no discernible trend in promotion chances over time. The NHS board dummy variables (not shown) showed that promotion was more likely in NHS boards outside Greater Glasgow, Lothian, and Grampian NHS boards.

Full sample results (table 3) assume that the promotion process is identical for men and women. We then dropped this assumption and investigated sex differences in promotion (table $3^{3}$ ). Even after part time working, years since graduation, and all other covariates are controlled for, women are less likely to be promoted than men. The impact of the country of qualification on promotion probability is similar if the doctor holds overseas qualifications, although women seem to have slightly higher chances than men if they qualified elsewhere in the UK.

Having an honorary contract is associated with promotion only for men. Years since graduation have a positive effect for both sexes, slightly higher for men, possibly because this variable may have absorbed some bias owing to higher past unobserved rates of part time work (or other unobserved factors that are correlated with part time work) by women, over and above those represented by the variable part time work that refers to the last two years before promotion. Part time contracts are negatively associated with promotion for both sexes, although this association reaches significance only for women. The fact that fewer than $1 \%$ of men work part time may account for the absence of precise estimates for men. Changes from part time working to full time working in the two years preceding promotion are not related to sex, although again the odds ratio is higher for women but the number that make this change are small.

\section{Discussion}

Having an honorary contract in the years before promotion is associated with a higher probability of promotion to consultant. This may reflect the importance of exposure to teaching and research during medical training, although this seems to matter only for men. Hospital doctors who work part time, especially women, are less likely to be promoted. This may reflect less accumulated experience. It may also reflect inflexibilities in the career structure, as this result is consistent with other evidence of an inflexible hospital medical career structure, which has shown that although part-time working among general practitioners has increased, part time working among hospital doctors fell during the 1990s in Scotland. ${ }^{4}$

\section{Differences by sex}

Women are less likely to get promoted than men, even after experience, part time working, and other factors are controlled for. We found no explanation or justification why sex on its own should matter. Whether this is because of discrimination in the promotion process requires further research into variations in the criteria for promotion. This is consistent with sex imbalances after promotion in the award of discretionary points and distinction awards. ${ }^{8}$ As the proportion of women in medicine increases, their stronger preference for part time work is likely to reduce the pool of doctors available for promotion unless inflexibilities in the career structure are dealt with.

Table 3 Logistic regression results (dependent variable $=1$ if promoted, 0 if not promoted) *

\begin{tabular}{|c|c|c|c|c|c|c|}
\hline \multirow[b]{2}{*}{ Variable } & \multicolumn{2}{|c|}{ Complete sample } & \multicolumn{2}{|c|}{ Women only } & \multicolumn{2}{|c|}{ Men only } \\
\hline & Odds ratio $(95 \% \mathrm{CI})$ & $P$ value & Odds ratio $(95 \% \mathrm{CI})$ & $P$ value & Odds ratio $(95 \% \mathrm{CI})$ & $P$ value \\
\hline Qualified England, Wales, $\nmid$ or Northern Ireland $(=1)$ & 0.65 (0.52 to 0.82$)$ & 0 & $0.70(0.45$ to 1.08$)$ & 0.111 & $0.61 \quad(0.46$ to 0.80$)$ & 0 \\
\hline Qualified non-UK† $(=1)$ & $0.37(0.28$ to 0.50$)$ & 0 & 0.34 (0.17 to 0.69$)$ & 0.003 & 0.34 (0.24 to 0.49$)$ & 0 \\
\hline Honorary contract‡ $(=1)$ & 1.37 (1.03 to 1.83 ) & 0.029 & 1.04 (0.57 to 1.89$)$ & 0.889 & 1.40 (1.00 to 1.97$)$ & 0.049 \\
\hline Women $(=1)$ & 0.73 (0.60 to 0.90$)$ & 0.004 & - & & - & \\
\hline No of years since graduation & 5.98 (4.94 to 7.23 ) & 0 & 5.77 (4.25 to 7.85$)$ & 0 & 5.94 (4.63 to 7.63 ) & 0 \\
\hline No of years since graduation squared & $0.47(0.23$ to 0.94$)$ & 0 & 0.55 (0.19 to 1.65$)$ & 0 & $0.52(0.20$ to 1.32$)$ & 0 \\
\hline Part time contractł $(=1)$ & $0.27 \quad(0.17$ to 0.42$)$ & 0 & 0.24 (0.14 to 0.41$)$ & 0 & 0.37 (0.07 to 2.01) & 0.247 \\
\hline Change from working part time to full time $\ddagger(=1)$ & 1.81 (0.81 to 4.01$)$ & 0.147 & 1.69 (0.69 to 4.12) & 0.253 & 3.64 (0.30 to 44.75$)$ & 0.313 \\
\hline No of doctor years & \multicolumn{2}{|c|}{7043} & \multicolumn{2}{|c|}{2634} & \multicolumn{2}{|c|}{4237} \\
\hline Likelihood ratio test§ $\chi^{2}$ (df) & \multicolumn{2}{|c|}{$1605(25)-P<0.0001$} & \multicolumn{2}{|c|}{$529(24)-P<0.0001$} & \multicolumn{2}{|c|}{$1058(24)-P<0.0001$} \\
\hline
\end{tabular}

Likelihood ratio test§ $\chi^{2}$ (df) $1605(25)-\mathrm{P}<0.000$

tReference category: qualified in Scotland.

†ln the two years preceding promotion.

$\S$ The likelihood ratio test is a measure of the joint statistical significance of all included independent variables. Its value follows the $\chi^{2}$ distribution. 


\section{Differences by place of graduation}

The place of graduation is associated with promotion prospects, possibly due to differences in the quality of information about the doctor's skills and ability. However, in view of the fact that doctors wishing to become consultants are individuals whose ability will have been more recently shown through the training process, there is no clear explanation why the place of graduation should matter.

The finding that promotions are more likely to be granted by those NHS boards outside of the main metropolitan areas of Scotland is likely to reflect the higher turnover of hospital consultants in NHS boards without teaching hospitals or tertiary services.

\section{Limitations of the study}

Our results come with several caveats. The data include only promotions that took place within NHS Scotland and rely on the accuracy and completeness of information sent to the information services division by hospitals. The measure of experience used (years since graduation) is not perfect, as it does not account fully for accumulated experience that may be different for men and women. The finding that women are less likely to be promoted may in part reflect this. Investigating this point would require complete data on employment history since graduation. The data will also include doctors in the training grades who may not want to become a consultant, and the results may be partly reflecting the preferences of this group, who are more likely to be female and work part time. However, this group is likely to be small.

\section{Conclusions}

The achievement of current government targets for the numbers of consultants is influenced by the promotion process and the quality control exercised by the royal colleges. As the proportion of female doctors increases, it will be difficult to meet government targets unless the promotion process is re-examined. This should focus on the weight given to individuals' skills and ability and the flexibility of contracts and working conditions. Safeguards will need to be in place to ensure that factors less likely to be related to ability or performance (such as sex, place of graduation, or part time working) will not influence promotion chances. Since 2000, when the data used in this paper finish, several changes have been introduced that have altered the career structures of hospital doctors. These include the Calman reforms, Modernising Medical Careers, further proposals for reform of the staff or associate specialist grades, and new contracts for junior doctors and consultants. It is unclear what impact these changes will have on the issues discussed in this paper.

Contributors: KM and AS shared all aspects of this work equally. Thanks to the Information Services Division Scotland for providing data, and to Gillian Needham, Michael Goldacre, and Doug Altman for helpful comments on an earlier version of this paper.

\section{What is already known on this topic}

Little rigorous research has been conducted into the promotion of hospital doctors to consultant level

The study of the promotion process in the NHS is crucial for the design of evidence based policies on human resource management

\section{What this study adds}

The adjusted probability of promotion of female hospital doctors to consultant level is considerably lower than that of male doctors

Graduates from overseas and doctors working part time are less likely to be promoted

Doctors who held an honorary contract and those working in non-metropolitan NHS boards are more likely to be promoted

Explicit promotion criteria are needed so that the government's goal of a consultant led NHS can be met

Funding: The Health Economics Research Unit is funded by the Chief Scientist Office (CSO) of the Scottish Executive Health Department. AS was funded through the Chief Scientist Office's core funding of the Health Economics Research Unit. KM was funded by the University of Aberdeen. The data were obtained for research funded by the Scottish Executive Health Department on NHS labour markets in Scotland. KM is guarantor.

Competing interests: None declared.

1 Department of Health. The NHS plan. A plan for investment. A plan for reform. Command paper 4818-I. London: Stationery Office, 2000.

2 Scottish Executive. Our national health. A plan for action, a plan for change. Edinburgh: Scottish Executive, 2000.

3 UK Departments of Health. Modernising medical careers: the next steps. London: DoH, 2004.

4 Elliott R, Mavromaras K, Scott A, Bell D, Antonazzo E, Gerova V, van der Pol M. NHS labour markets in Scotland. Final report to the Scottish Executive Health Department. Aberdeen: Health Economics Research Unit, 2002.

5 Wooldridge JM. Econometric analysis of cross section and panel data. London, England: MIT Press, 2002:453-509 (chapter 15).

6 Baltagi B. Econometric analysis of panel data, 2nd ed. Chichester: John Wiley, 2001:11-27 (chapter 2).

Stata Corporation. Stata. Cross-sectional time-series command xtlogit was used. Reference manual, release 8. Texas: Stata Corporation, 2003.

8 Lambert TW, Goldacre MJ, Vallance E, Mallick N. Characteristics of consultants who hold distinction awards in England and Wales: database analysis with particular reference to sex and ethnicity. BMJ 2004;328:1347.

(Accepted 16 September 2005)

doi 10.1136/bmj.38628.738935.3A

Melbourne Institute of Applied Economic and Social Research, University of Melbourne, Parkville, VIC 3010, Australia

Kostas Mavromaras professor

Anthony Scott professor

Correspondence to: K Mavromaras k.mavromaras@unimelb.edu.au 